\title{
CLINICO-AETIOLOGICAL SPECTRUM OF SEIZURE IN TERTIARY CARE HOSPITAL IN EASTERN UTTAR PRADESH
}

Pavan Kumar Singh', Azhar Ali Khan'2, Sarvesh Kumar Chaudhary33, Mahim Mittal', Reeta Singh ${ }^{5}$

${ }^{1}$ Associate Professor, Department of Medicine, BRD Medical College, Gorakhpur, Uttar Pradesh. ${ }^{2}$ Associate Professor, Department of Medicine, BRD Medical College, Gorakhpur, Uttar Pradesh.

${ }^{3}$ Senior Resident, Department of Medicine, BRD Medical College, Gorakhpur, Uttar Pradesh.

4 Professor and HOD, Department of Medicine, BRD Medical College, Gorakhpur, Uttar Pradesh.

${ }^{5}$ Assistant Professor, Department of Obstetrics and Gynaecology, BRD Medical College, Gorakhpur, Uttar Pradesh.

\section{ABSTRACT}

\section{BACKGROUND}

There is limited data regarding aetiology of acute seizure episodes from the developing countries. Current study aims to study clinical spectrum of seizure in hospitalised patients in Nehru Hospital, BRD Medical College, Gorakhpur, Eastern Uttar Pradesh and to study risk factors and cause of seizure.

\section{METHODOLOGY}

This was a hospital-based, prospective observational study carried out in the Department of Medicine, BRD Medical College, Gorakhpur, from January 2015 to December 2015. All cases aged more than 16 years admitted to medical wards with seizures were included for the study except those patients with history of pseudoseizure and patients with insufficient clinical data for seizure diagnosis. Variables observed were demographics, clinical presentations, laboratory tests, electroencephalography brain imaging studies, clinical spectrum and hospital course.

\section{RESULTS}

A total of 200 patients were admitted for seizures with 123 (61.5\%) males and 77 (38.5\%) females; 55\% presented with fever and most of patients (32\%) were $<26$ years of age. Generalised tonic-clonic seizures were the most common seizure type (78\%), CNS infections $43.5 \%$ and CVA 20\% were common aetiologies. In Eastern U.P. among neuroinfections, Acute Encephalitic Syndrome (AES) was most common cause of seizure unlike other areas. NCC infection was contributing $21 \%$ cases of AES. While during course of study, 6 cases of JE were reported. Abnormal brain images were found in 116 (58\%) patients. Most common abnormality in CT was Granuloma (10.5\%). CT changes was more common in focal as compared to generalised seizures (P 0.001). In CNS infections, NCC was most common cause of focal seizure. CVA was found to be the most common aetiology in patients with above 40 years of age.

\section{CONCLUSION}

Aetiology may vary from region to region, but CNS infections and CVA are common causes of seizures in adults. In young population, AES is the most common cause of seizure in Eastern UP. Neuroimaging, cerebrospinal fluid examination and electrolyte examination apart from detailed history and neurological examination is essential for definitive diagnosis of seizure.

\section{KEYWORDS}

Neurocysticercosis NCC, Acute Encephalitic Syndrome AES, Electroencephalography (EEG).

HOW TO CITE THIS ARTICLE: Singh PK, Khan AA, Chaudhary SK, et al. Clinico-aetiological spectrum of seizure in tertiary care hospital in Eastern Uttar Pradesh. J. Evolution Med. Dent. Sci. 2016;5(78):5787-5790, DOI: 10.14260/jemds/2016/1306

\section{INTRODUCTION}

The seizure was attributed to the god of the moon and many supernatural powers. After a long circuit through ages of magic, black humours and black disinterest, medical thought has returned to the affirmation that epilepsy like many other diseases is the root in natural causes.

Seizure is one of the most common neurological disorder and about $10 \%$ population experience in their lifetime. ${ }^{1}$ Seizures as the first presenting event can be the feature of acute medical or neurological disorder.

Financial or Other, Competing Interest: None.

Submission 08-09-2016, Peer Review 20-09-2016,

Acceptance 23-09-2016, Published 27-09-2016.

Corresponding Author:

Dr. Pavan Kumar Singh

Associate Professor

Department of Medicine

BRD Medical College,

Gorakhpur-273013,

Uttar Pradesh, India.

E-mail: pavan.singh@rediffmail.com

DOI: $10.14260 /$ jemds/2016/1306
Seizure is a paroxysmal event due to abnormal excessive or synchronous neuronal activity in the brain. Determining the type of seizure that has occurred is essential for focusing the diagnostic approach on particular aetiologies, selecting the appropriate therapy and providing potentially vital information regarding prognosis. The prevalence and incidence of seizure is lower in developed countries in comparison with developing countries. Understanding pattern and risk factors of seizure cases will help in suggesting appropriate preventive measures.

A recent meta-analysis of published and unpublished studies puts the overall prevalence rate of seizure in India at 5.59 per 1,000 population ${ }^{2}$ with no statistically different rates between men and women or urban and rural residence population. WHO estimates that eight people per 1000 worldwide have this disease. ${ }^{3}$

Classification of seizures is more than an academic exercise, as it determines subsequent decisions on evaluation and treatment.

The aetiology of seizures is different in India and other developing countries as compared to the developed world. 
Tuberculoma and neurocysticercosis have relatively high frequency in India. ${ }^{4}$

A systematic approach to confirming the diagnosis, establishing aetiology and determining likelihood of recurrence will aid the clinician in provision of optimal care. Modern techniques like Computed Tomography, Magnetic Resonance Imaging (MRI) and Positron Emission Tomography (PET) and SPECT are planned for intractable epilepsy for definitive localisation of epileptic focus. These advanced investigation are very important in patient with intractable epilepsy for presurgical evaluation.

The basic principles of good epilepsy care however will not change: strive for the best seizure control, maintain vigilance for side effects and continue to educate and advocate for the person with problems.

It is very surprising that till date very limited data available on clinical spectrum of seizure in Eastern Uttar Pradesh. In a design to analyse aetiology, it is desirable to select incident cases instead of prevalent cases. There are hardly any major prospective study on clinico-aetiological spectrum of seizure in India, which makes our study special as it is probable first study to evaluate aetiology and clinical profile of adult onset seizures in Eastern Uttar Pradesh.

\section{MATERIALS AND METHODS}

All patients with seizure included in study were in-patient of Nehru Hospital, BRD Medical College, Gorakhpur, UP. About 200 patients were taken and duration of study was 1 year, i.e. January 2015 to December 2015.

All patients were diagnosed and classified using the classification proposed by the International League Against Epilepsy.

\section{Inclusion Criteria}

- Age $>16$ presenting with seizure.

\section{Exclusion Criteria}

- Pseudoseizure.

- Syncopal attacks.

The investigations like blood sugar, electrolytes including calcium, blood urea, serum creatinine, Liver Function Test (LFT), complete haemogram including ESR were done on all the patients.

Specific investigations wherever indicated viz. CT scan/MRI brain - plain and contrast, Electroencephalography (EEG), Cerebrospinal Fluid (CSF) analysis, IgM ELISA for Japanese Encephalitis virus and enterovirus in serum and CSF IgM and NS1 antigen for dengue virus, electrocardiograph (ECG), X-ray-Chest.

The aetiology of seizures was determined on the basis of medical history, neurologic examination, various investigations, the EEG recording and CT scan/MRI brain.

\section{RESULTS}

In this studied population 200 patients were taken, out of which 77 patients were female. Mean age of patients is 40.7 . Mean age of female patients is 37.3 with SD 17.7, while mean age of male patients 42.8 with SD 19.1. Male:female ratio is 1.56 .

Five clinical findings were commonly found in patients. The most common presenting symptoms were altered sensorium (80\%) and fever (55\%), which was present followed by headache (50\%), vomiting (43\%) and focal deficit including hemiparesis (21\%).

\begin{tabular}{|c|c|c|c|c|c|}
\hline 항 & 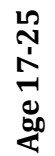 & 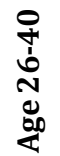 & 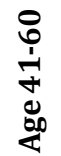 & $\begin{array}{l}0 \\
0 \\
\hat{0} \\
0 \\
0\end{array}$ & 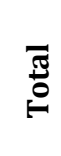 \\
\hline \multicolumn{6}{|c|}{ 1. Vascular Events 40} \\
\hline $\begin{array}{l}\text { a) CVA } \\
\text { (Ischaemic/Haemo } \\
\text { rrhagic) }\end{array}$ & - & 5 & 19 & 11 & 35 \\
\hline b) SDH & & & & & 1 \\
\hline c) CVT & 1 & & & & 1 \\
\hline d) $\mathrm{SAH}$ & & & & 2 & 2 \\
\hline E)AVM & & & 1 & & 1 \\
\hline \multicolumn{5}{|c|}{ 2. Neuroinfections } & 87 \\
\hline A. AES & 13 & 8 & 13 & 8 & 42 \\
\hline B. NCC & 12 & 3 & 6 & - & 21 \\
\hline C. TBM & 8 & 4 & 1 & 2 & 15 \\
\hline D. Malaria & 4 & 1 & 1 & & 6 \\
\hline E. HIV & & & 2 & & 2 \\
\hline $\begin{array}{l}\text { F. ADEM (Post } \\
\text { Infectious) }\end{array}$ & 1 & & & & 1 \\
\hline \multicolumn{5}{|c|}{ 3. Metabolic } & 24 \\
\hline A. Uraemia & 3 & & & & 3 \\
\hline B. Hypocalcaemia & & & 1 & & 1 \\
\hline $\begin{array}{l}\text { C. Hepatic } \\
\text { Encephalopathy }\end{array}$ & & 1 & & & 1 \\
\hline D. Hypoglycaemia & & & 1 & 1 & 2 \\
\hline E. Hyperglycaemia & & 1 & 1 & & 2 \\
\hline F. Hyponatraemia & 2 & 8 & 3 & 2 & 15 \\
\hline \multicolumn{5}{|c|}{ 4. Neoplastic } & 4 \\
\hline 5. Drug Default & 6 & 4 & 3 & 2 & 15 \\
\hline 6. Toxins & & & & & 6 \\
\hline 7. Others & & & & & 3 \\
\hline 8. Cryptogenic & 11 & 4 & 5 & 1 & 21 \\
\hline Total & & & & & 200 \\
\hline
\end{tabular}

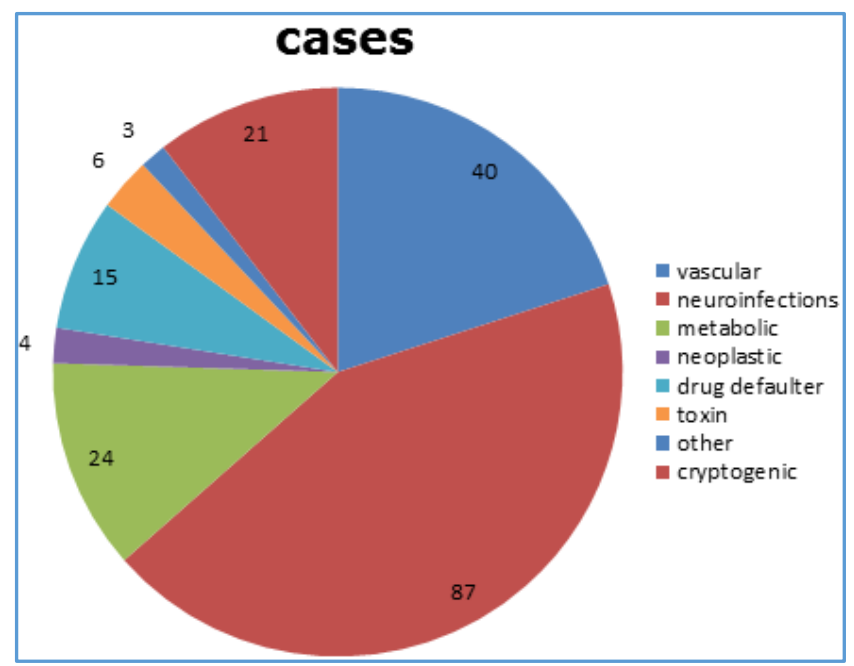

Fig. 1 


\begin{tabular}{|c|c|c|c|c|c|c|c|c|}
\hline Semiology & Infections & Vascular & Metabolic & Neoplastic & Toxins & Defaulters & Cryptogenic & Others \\
\hline GTCS & 68 & 28 & 21 & 1 & 5 & 13 & 17 & 3 \\
\hline Simple & 2 & & & & & & & \\
\hline Complex & 3 & 2 & 1 & & & & & \\
\hline $2^{0}$ Generalised & 11 & 8 & 1 & 3 & 1 & 1 & 1 & \\
\hline $\begin{array}{c}\text { Status } \\
\text { Epilepticus } \\
\end{array}$ & 3 & 2 & 1 & & & 1 & 3 & \\
\hline
\end{tabular}

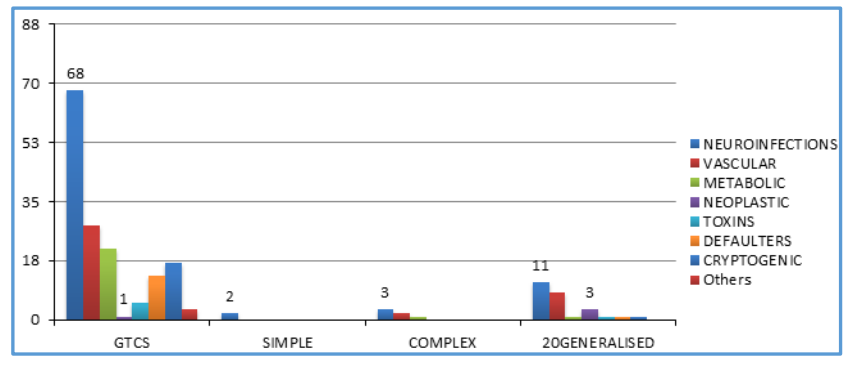

Fig. 2

Neuroimaging (CT/MRI scan) was found to be normal in 116 (58\%) patients seizures. Most common abnormality observed was granuloma in 21 patients followed by infract in 20 , haemorrhage in 15 , hydrocephalus in 6 , Tuberculoma in 2 and Tumours in 4 patients. In 27 patients of focal seizure, CT was abnormal while in 53 patients of GTCS CT head was normal.

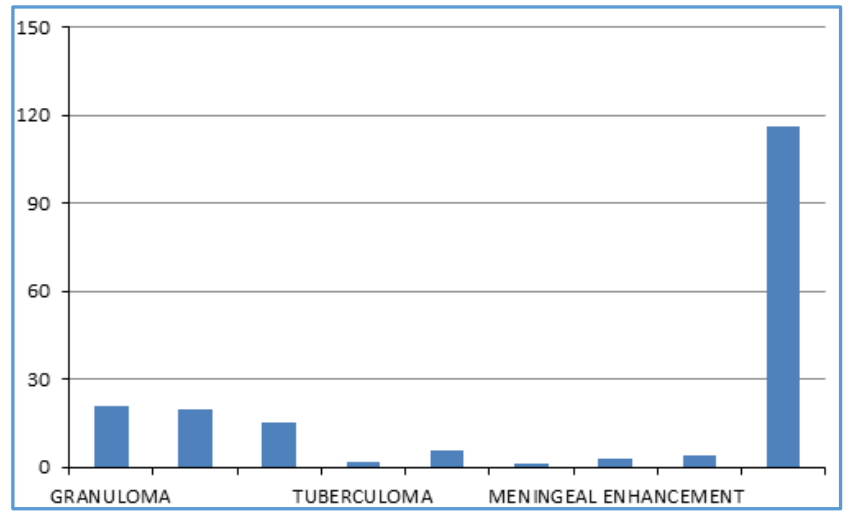

Fig. 3

In 8 patients of AES out of 42 three patients had mild meningeal enhancement and 3 had calcified granuloma, 1 had hydrocephalus, 1 had subcortical oedema, rest 34 patients of AES having normal CT. Normal CT head was found in $80.9 \%$ patients. In AES patient, most common CT findings was mild meningeal enhancement and calcified granuloma.

\begin{tabular}{|c|c|c|}
\hline Aetiology & Male & Female \\
\hline JE & 4 & 2 \\
\hline HSV & 0 & 2 \\
\hline TBM & 1 & 2 \\
\hline Unknown & 20 & 6 \\
\hline Dengue & 0 & 1 \\
\hline Malaria & 1 & 1 \\
\hline Typhoid & 1 & 1 \\
\hline Total & $\mathbf{2 7}$ & $\mathbf{1 5}$ \\
\hline \multicolumn{2}{|c|}{ Table 3: AES Patients with Various Aetiology } \\
\hline
\end{tabular}

\section{DISCUSSION}

There are very few major hospital-based studies, which evaluated seizures prospectively in adults especially from developing countries.
Aetiological spectrum depends on age, sex, geography and medical setting. In our study, out of 200 patients most (32\%) of patients were in the age group of (17-25) years and (16.5\%) were in the age group of $>60$ years and which correlated with study done by Sridharan R, Murthy BN, ${ }^{2}$ Thomas SV and Sarma PS. ${ }^{5}$

In younger age group (17-25 yrs.), most common cause of seizure was neuroinfections. Among neuroinfections, AES was the commonest cause followed by Neurocysticercosis (NCC). AES (Acute Encephalitic Syndrome) which was most common aetiology of seizure 21\% (42 out of 200), these include patients of Japanese Encephalitis (JE), HSV encephalitis, viral encephalitis due to unknown aetiology, some cases of malaria and TBM and encephalitis due to dengue and typhoid.

As this North-East UP region is a belt more prone for encephalitis, so AES was most common neuroinfection. While study done by Sriharsha K and Malali, ${ }^{6}$ Narayanan J.T., Rao B.S., Vani M.S., Varma $^{7}$ and Murthy $^{8}$ reveal NCC (Neurocysticercosis) as most common neuroinfection.

Most common type of seizure admitted in Medicine Department were generalised type (156) (78\%) followed by $17 \%$ as focal seizure, while $5 \%$ patients admitted to emergency as a case of status epilepticus. Similar observations were found in other studies.2,9,10

The reason for higher percentage of generalised seizure disorder seems to be the patient's selection criteria, i.e. only hospitalised patients were taken into the study. Patients with focal seizure usually consult OPD treatment and require less admission as they are clinically stable.

NCC was the most common cause of focal seizure followed by CVA and neoplastic causes as in study of Sahil Mehta, Gagandeep Singh ${ }^{11}$ and study of Pritpal. ${ }^{12}$

Among all causes of seizure in studied population, neuroinfections were most common cause followed by cerebrovascular accidents and metabolic causes. Similar observation was made in studies by JNK Murthy; Jaishree T, Narayan, ${ }^{8}$ Rao B.S., Vani M.S. and Varma, ${ }^{7}$ while vascular causes were more frequent cause in study of developed nations. $13,14,15,16$

Among 40 patients with cerebrovascular accidents accounts for $20 \%$ of all causes, stroke accounted for 35 (Infarct - 20, Haemorrhage - 15) followed by SAH in 2 patients, 1 each AV malformation and cerebral venous thrombosis (CVT). These observations were similar to other Indian studies. $2,7,8$

Neuroimaging was performed in all patients in our study. CT head was found normal in 116 patients, while abnormal in 84 patients.

Abnormal CT head was found in (76.47\%) patients with focal seizure $(32.25 \%)$ with generalised seizure. CT changes were more common in focal as compared to generalised seizures (P 0.0001). Baheti et al ${ }^{17}$ who also found CT scan abnormalities in $50 \%$ of patients with partial seizures and $34.6 \%$ patients with generalised seizures. 
In our study most common CT finding in patients, NCC was Single Enhancing Lesion (SCEL) 57\%, while multiple enhancing lesion (4.76\%) and rest having calcified granuloma. Single lesion was the most common finding study by Singhi et al18 and Kotokey et al ${ }^{19}$ reported single lesion in $66.66 \%$, Rajshekhar et $\mathrm{al}^{4}$ reported single lesion in $60.88 \%$; Sahil Mehta and Gagandeep Singh ${ }^{11}$ reported single lesion in $86 \%$. Granuloma was also the most common neuroimaging finding in study done by Kaffle. ${ }^{20}$

This study illustrates that the aetiological spectrum of acute seizure(s) were different from that described in developed countries and CNS infections still account for a significant number of cases.

Most of the patients in the present study belongs to rural areas with endemicity of diseases like AES, Neurocysticercosis and Tuberculosis. Low socioeconomic status and poor personal hygiene contribute to higher percentage of infectious aetiology of seizure in present study and other studies from developing countries.

Most of the patients living in these areas are infected at younger age and become symptomatic with seizure at a younger age. Risk factors for stroke increases with age and contribute to higher chances of stroke in elderly. Management of seizure is always multi-modal, which constitutes treatment of cause, avoidance of precipitating factors, suppression of recurrent seizures by prophylactic therapy and addressing a variety of psychological and social issues.

\section{CONCLUSION}

This study showed neuroinfections were the most common cause of seizure in Eastern Uttar Pradesh region and AES was the most common neuroinfection. JE was common among AES cases. NCC was the most common cause of focal seizure. Vascular aetiology was common above age 40. Most common type of seizure semiology in study was generalised pattern. CT abnormalities were documented more in patients having focal seizure. Although neuroimaging and other investigations were important to establish the cause, but medical history and neurological examination are equally important for best management. As this Eastern Uttar Pradesh belt is more prone to different viral encephalitis, patient with seizure should be screened for AES with variable aetiology. Treatment should be planned based on aetiological factor for seizure for better outcome.

\section{ACKNOWLEDGEMENTS}

We express our sincere thanks and gratitude to the HOD, Medicine Department, BRD Medical College for permitting us to conduct this study and also for valuable support. I am extremely grateful to all our Assistant Professors and PG Residents for their constant source of cheer and encouragement throughout the study. I thank my wife Dr. Reeta Singh who have formed the back bone of my study, without them this work would not have been possible. I am also thankful to all paramedical staff of my neurological unit for technical support.

\section{REFERENCES}

1. Annegers JF, Hauser WA, Lee JR, et al. Incidence of acute symptomatic seizures in Rochester, Minnesota, 19351984. Epilepsia 1995;36(4):327-33.

2. Sridharan R, Murthy BN. Prevalence and pattern of epilepsy in India. Epilepsia 1999;40(5):631-6.

3. World Health Organization: epilepsy, epidemiology, aetiology and prognosis. WHO Factsheet 2001:165.

4. Rajshekhar V, Joshi DD, Doanh NQ, et al. Taenia solium taeniosis/cysticercosis in Asia: epidemiology, impact and issues. Acta Trop 2003;87(1):53-60.

5. Thomas SV, Sarma PS, Alexander M, et al. Epilepsy care in six Indian cities: a multicenter study on management and service. J Neurol Sci 2001;188(1-2):73-7.

6. Sander JW, Hart YM, Johnson AL, et al. National general practice study of epilepsy: newly diagnosed epileptic seizures in a general population. Lancet 1990;336(8726): 1267-71.

7. Rao BS, Vani MS, Varma GAR. The study of etiological profile in new onset seizures in Indian scenario. International Journal of Advances in Medicine 2015;2 (1):6-12.

8. Narayanan JT, Murthy JM. New onset acute symptomatic seizure in aneurological intensive care unit. Neurology India 2007;55(2):136-40.

9. Sriharsha K, Malali V. Clinical and etiological study of seizures in young adults. Indian Journal of Basic and Applied Medical Research 2015;4(2):76-83.

10. Saha SP, Bhattacharya S, Roy BK, et al. A Prospective incidence study of epilepsy in a rural community of WestBengal, India. Neurology Asia 2008;13:41-8.

11. Mehta S, Singh G. Electroclinical characteristics of newonset seizures associated with neurocysticercosis Neurology India 2014;62(2):159-63.

12. Singh P, Gupta SK, Gupta A. Onset of first seizure in adults: a prospective study from a tertiary hospital. J K Science 2014;16(3):126-130.

13. Sander JW. The epidemiology of epilepsy revisited. Curr Opin Neurol 2003;16(2):165-70.

14. Berges S, Moulin T, Berger E, et al. Seizures and epilepsy following strokes: recurrence factors. Eur Neurol 2000;43(1):3-8.

15. Sander JW, Shorvon SD. Epidemiology of the epilepsies. J Neurol Neurosurg Psychiatry 1996;61(5):433-43.

16. Hauser WA, Beghi E. First seizure definitions and worldwide incidence and mortality. Epilepsia 2008;(49 Suppl 1):8-12.

17. Baheti R, Gupta BD, Baheti R. A study of CT and EEG findings in patients with generalised or partial seizures in western Rajasthan. J Ind Acad Clin Med 2003;4(1):25-9.

18. Singhi P, Ray M, Singhi S, et al. Clinical spectrum of 500 children with neurocysticercosis and response to albendazole therapy. J Child Neurol 2000;15(4):207-13.

19. Kotokey RK, Lynrah KG, De A. A clinico-serological study of neurocysticercosis in patients with ring enhancing lesions in CT scan of brain. J Assoc Physicians India 2006;54:36670.

20. Kafle DR. Clinical profile of patients with partial seizure. Journal of Nobel Medical College 2014;3(No. 1)5):31-4. 